\title{
Common Diagnoses and Outcomes in Elderly Patients Who Present to the Emergency Department with Non-Specific Complaints
}

\author{
Kathleen Quinn, MD*; Michael Herman, MD; Daren Lin, MD; Wendy Supapol, PhD ${ }^{\ddagger}$; Andrew \\ Worster, MD, MSc ${ }^{\ddagger}$
}

\section{ABSTRACT}

Objective: Elderly patients often present to the emergency department (ED) with non-specific complaints. Previous studies indicate that such patients are at greater risk for lifethreatening illnesses than similarly aged patients with specific complaints. We evaluated the diagnoses and outcomes of elderly patients presenting with non-specific complaints.

Methods: Two trained data abstractors independently reviewed all records of patients over 70 years old presenting (to two academic EDs) with non-specific complaints, as defined by the Canadian Emergency Department Information System (CEDIS). Outcomes of interest were ED discharge diagnosis, hospital admission, length of stay, and ED revisit within 30 days.

Results: Of the 743 patients screened for the study, 265 were excluded because they had dizziness, vertigo, or a specific complaint recorded in the triage notes. 419 patients $(87.7 \%)$ presented with weakness and 59 patients (12.3\%) presented with general fatigue or unwellness. The most common diagnoses were urinary tract infection (UTI) $(11.3 \%)$, transient ischemic attack (TIA) (10.0\%), and dehydration (5.6\%). There were 11 hospital admissions with median length of stay of five days. Eighty-one (16.9\%) patients revisited the ED within 30 days of discharge. Regression analysis indicated that arrival to the ED by ambulance was independently associated with hospital admission.

Conclusions: Our results suggest that elderly patients presenting to the ED with non-specific complaints are not at high risk for life-threatening illnesses. The most common diagnoses are UTI, TIA, and dehydration. Most patients can be discharged safely, although a relatively high proportion revisit the ED within 30 days.

\section{RÉSUMÉ}

Objectif: II est fréquent que des personnes âgées consultent au service des urgences (SU) pour des symptômes généraux. $\mathrm{D}$ 'après des études antérieures, ces patients connaissent un risque plus grand de maladies potentiellement mortelles que les patients de même âge ayant des symptômes précis. Aussi les auteurs ont-ils évalué les diagnostics posés chez des personnes âgées examinées pour des symptômes généraux, de même que l'issue.

Méthode: Deux personnes formées à l'abstraction de données ont examiné, chacune de leur côté, tous les dossiers de patients âgés de plus de 70 ans, qui ont consulté dans deux SU d'hôpitaux universitaires pour des symptômes généraux tels qu'ils sont définis dans le Canadian Emergency Department Information System (CEDIS). Les principaux critères d'évaluation comprenaient le diagnostic au moment du congé du SU, I'hospitalisation, la durée de séjour et les nouvelles consultations au SU dans les 30 jours suivants.

Résultats: Sur 743 patients présélectionnés pour l'étude, 265 ont été écartés parce qu'on faisait déjà mention d' $d^{\prime}$ "étourdissements " ou de "vertiges " ou encore de symptômes précis dans les notes relatives au triage. Sur le nombre restant de patients, $419(87,7 \%)$ présentaient de la faiblesse, et 59 $(12,3 \%)$, de la fatigue générale ou un état de malaise. Les diagnostics les plus fréquents étaient une infection des voies urinaires (IVU) (UTI) $(11,3 \%)$, un accident ischémique transitoire (AIT) $(10,0 \%)$ et la déshydratation $(5,6 \%)$. II y a eu 11 hospitalisations, et la durée médiane de séjour était de 5 jours. Quatre-vingt-un patients $(16,9 \%)$ ont consulté de nouveau au SU dans les 30 jours suivant le congé. Une analyse de régression a révélé que l'arrivée en ambulance au SU était en relation indépendante avec I'hospitalisation.

Conclusions: D'après les résultats de l'étude, les personnes âgées qui consultent au SU pour des symptômes généraux ne connaîtraient pas un risque élevé de maladies potentiellement mortelles. Les diagnostics les plus fréquents sont les IVU, les AIT et la déshydratation. La plupart des patients peuvent obtenir leur congé du service en toute sécurité, et ce, malgré le fait qu'une proportion relativement élevée consulte de nouveau au SU dans les 30 jours suivants.

Keywords: elderly, diagnosis, weakness

From the * Internal Medicine Residency Program, McMaster University, Hamilton, ON; †Family Medicine Residency Program, Dalhousie University, Halifax, NS; and ¥Division of Emergency Medicine, McMaster University, Hamilton, ON

Correspondence to: Kathleen Quinn, MD, McMaster University, MDCL room 3101A, 1280 Main Street West, Hamilton, ON, Canada, L8S4K1; Email kathleen.quinn@medportal.ca 


\section{INTRODUCTION}

As the population ages, there are increasing numbers of elderly patients presenting to the emergency department (ED) each year. ${ }^{1}$ Numerous studies have found that older adults use emergency services more frequently and have higher hospital admission rates $(>65 \%)$ than younger persons. $^{2-5}$ Older patients undergo more frequent diagnostic testing than younger patients, and have longer lengths of stay (LOS) in hospital with an increased rate of adverse outcomes. ${ }^{2}$ Patient age, triage score, heart rate, diastolic blood pressure, and chief complaint have all been found to be independently associated with hospital admission in this population. ${ }^{3} \mathrm{Up}$ to $44 \%$ of elderly patients have also been found to return to the ED within three months of discharge from their index ED visit, and 19\% of these patients returned to the ED within 30 days. $^{5}$ Factors independently associated with a return visit to the ED include a history of heart disease, hospital admission within the previous six months, and alcohol use. ${ }^{5}$ These findings collectively indicate that the evaluation and management of older patients is complicated, at least in part, by the fact that these patients often suffer from multiple comorbidities, polypharmacy, cognitive disorders, and not infrequently a failure of the referring health care provider or facility to provide appropriate communication and documentation. , $^{2,7}$

The evaluation of older patients is further complicated when they present with a nonspecific complaint (NSC). Up to $20 \%$ of patients over the age of 75 present with NSCs such as fatigue, general weakness, dizziness, and recent falls. ${ }^{8}$ Of concern, some reports suggest that elderly patients with NSCs might be more acutely ill and suffer worse outcomes than elderly patients with specific complaints. More than $50 \%$ of elderly patients with a vague presenting complaint at triage have been found to require acute medical attention after initial medical evaluation, and a presenting complaint of "general disability" has been found to be highly associated with in-hospital death.,10 Another study reported that during a 30-day follow-up period of elderly patients presenting to the $\mathrm{ED}$ with an NSC, a serious condition, defined as "potentially lifethreatening or requiring early intervention to prevent serious health status deterioration," was diagnosed in 59\% of patients, $6 \%$ of whom died within 30 days. $^{6}$ In a cross-sectional study of 633 patients with NSCs, $12.2 \%$ of patient presentations were associated with a drug-related problem, such as polypharmacy, or problematic drug classes such as diuretics, benzodiazepines, antidepressants, and anti-convulsants. ${ }^{11}$

The objectives of our study were to determine the most common diagnoses and outcomes of elderly patients presenting with general weakness, fatigue, and unwellness to the ED of two Canadian tertiary care hospitals and to identify factors independently associated with hospital admission and in-hospital mortality. We also sought to determine the rate of return visits to the $\mathrm{ED}$ within 30 days and the associated outcomes.

\section{METHODS}

\section{Study design}

A retrospective medical record review study of all patients $\geq 70$ years old presenting to two EDs with non-specific complaints (NSCs) over a one-year period, from January 1, 2010 to December 31, 2010 inclusive, was undertaken. Research ethics board (REB) approved was obtained from the Hamilton Health Sciences/ Faculty of Health Sciences REB.

\section{Study setting and population}

This study was conducted in the EDs of Hamilton General Hospital and Juravinski Hospital, located in Hamilton, Ontario, a city with a population of approximately 500,000. Together, both these centers had an annual ED census of 72,941 in 2010, of whom 15,562 were elderly.

\section{Selection of subjects}

We selected all hospital records of all elderly patients who presented to the ED between January 1, 2010 and December 31, 2010 with a presenting complaint of general weakness, fatigue or feeling unwell. We identified NSCs using the Canadian Emergency Department Information Systems (CEDIS v1.1.1), a standardized list of patient presenting complaints to Canadian EDs, and corresponding International Classification of Disease (ICD-10) codes and definitions. Our selection of cases was based on a previously published definition of "NSC," which included "all complaints that were not part of a set of specific complaints or signs or where an initial working diagnosis cannot be definitively established." We excluded presenting complaints of dizziness or 
vertigo due to ambiguity in and between the definitions of the two terms. Only the index ED visit was included for patients who presented to the ED with NSCs on multiple occasions. We also reviewed the charts of all patients who returned to the ED within 30 days of their index visit to determine whether they were admitted and what their survival status was.

\section{Study protocol and measurement}

We applied the published guidelines for medical record review studies. ${ }^{12,13}$ Specifically, two trained data abstractors used standardized data collection procedures and forms to independently abstract patient data. The data collection form included the following components collected for each patient: age, sex, method of arrival to ED (ambulance, wheelchair, ambulatory), Canadian Triage and Acuity Scale (CTAS) score (a five-point scale ranging from level 1 , resuscitation, to level 5 , non-urgent), vital signs at triage, presenting complaint, ED visit in the previous 30 days, $\mathrm{ED}$ discharge diagnosis, discharge disposition (home, admission to hospital, admission to ICU, underwent surgery), LOS in hospital if admitted, ED re-visit within 30 days after discharge, and in-hospital mortality. To assess the reliability of the data abstractors, each data abstractor reviewed $10 \%$ of the other's data collection. Discrepancies were to be deferred to an arbitrator if not resolved by consensus.

\section{Data analysis}

Descriptive statistics were used to summarize the findings. We also conducted a stepwise binary logistic regression to determine any associations between selected variables defined a priori by consensus and admission to hospital. The following candidateindependent variables were selected: abnormal vital signs, age, male, recent ED visit or admission, CTAS 1 or 2, and arrival by ambulance. We did not include mortality as a part of the outcome variable, as all patients who died within the 30-day follow-up were admitted. For each of the independent variables analyzed, odds ratios and associated 95\% confidence intervals were calculated and reported.

\section{RESULTS}

Based on the CEDIS presenting complaint, 743 patients were included in the study initially, but upon review of presenting symptoms in the triage notes, 265 patients were excluded due to specific presenting complaints, dizziness, or vertigo, resulting in a final number of 478 cases for analysis. The inter-rater reliability assessment revealed four (0.8\%) discrepancies in total, all of which were resolved by consensus.

Table 1 provides characteristics of the study population, and shows that $54.8 \%$ of patients were female and $45.2 \%$ were male. The average age was 81.9 years (SD 6.2). Most (59.2\%) patients arrived by ambulance and the median CTAS score reported was 3. General weakness was the predominating (87.7\%) complaint. Within 30 days prior to their current presentation, 74 patients $(15.5 \%)$ had visited the ED and 38 patients (7.9\%) had been admitted to hospital within the previous 30 days.

Table 2 provides the diagnoses of the study patients. The most common diagnoses, in order of frequency, were urinary tract infection (UTI) $(11.3 \%)$, transient ischemic attack (TIA) (10.0\%), and dehydration (5.6\%).

In total, 11 patients (2.3\%) were admitted to hospital. The discharge diagnoses were: palliation (two patients); anemia (one patient); cerebrovascular accident (one patient); acute coronary syndrome (two patients); normal pressure hydrocephalus (one patient); gastrointestinal bleed (one patient); hypotension (one patient); and subdural hematoma (two patients). Of the aforementioned 11 patients, two had a previous ED visit in the past 30 days. None of the admitted patients had been hospitalized within the previous 30 days. For admitted patients, the mean LOS in hospital was 5.5 days, with a range of one to 44 days and a mean of three days. One patient was transferred to the ICU and stayed for six days before dying. Of the admitted patients, four $(36.4 \%)$ died in-hospital. The charted diagnoses for the patients who died in hospital were: ST-elevation myocardial infarction (one patient), intracranial bleed (two patients), and hypotension secondary to dehydration/constipation (one patient). The two patients with a discharge diagnosis of "palliative" survived to hospital discharge, and their destination after discharge (hospice or home) was not recorded.

Table 3 provides the CTAS scores and outcomes for the study population. Patients admitted to hospital came from each triage category; those who died in hospital came from all but the lowest CTAS categories. Results of the regression analysis are provided in Table 4, and indicate that only one of the six 
Diagnoses and outcomes for elderly patients with non-specific complaints

\begin{tabular}{|c|c|}
\hline Patient Characteristic & $\begin{array}{c}\text { Summary } \\
\text { Distribution* }\end{array}$ \\
\hline Age & 81.9 years, SD 6.19 \\
\hline \multicolumn{2}{|l|}{ Sex } \\
\hline Male & $216(45.2)$ \\
\hline Female & $262(54.8)$ \\
\hline \multicolumn{2}{|l|}{ Method of Arrival } \\
\hline Ambulance & $283(59.2)$ \\
\hline Wheelchair & $58(12.1)$ \\
\hline Ambulatory & $137(28.7)$ \\
\hline \multicolumn{2}{|l|}{ CTAS Triage Score } \\
\hline I: Resuscitation & $7(1.46)$ \\
\hline II: Emergent & $58(12.1)$ \\
\hline III: Urgent & $362(75.7)$ \\
\hline IV: Less Urgent & $49(10.2)$ \\
\hline V: Non-Urgent & $1(0.21)$ \\
\hline \multicolumn{2}{|l|}{ Presenting Complaint } \\
\hline General Weakness & $419(87.7)$ \\
\hline Fatigue/Feeling Unwell & 59 (12.3) \\
\hline \multicolumn{2}{|l|}{ Vital Signs } \\
\hline Temperature $36.0-38.0^{\circ} \mathrm{C}$ & 441 (92.3) \\
\hline Temperature $35.0-36.0^{\circ} \mathrm{C}$ & $29(6.1)$ \\
\hline Temperature $<35.0^{\circ} \mathrm{C}$ & $2(0.4)$ \\
\hline Temperature $>38.0^{\circ} \mathrm{C}$ & $6(1.3)$ \\
\hline Heart Rate 50-100 & $418(87.4)$ \\
\hline Heart Rate $<50$ & $6(1.3)$ \\
\hline Heart Rate $>100$ & $54(11.3)$ \\
\hline Respiratory Rate 12-20 & $452(94.6)$ \\
\hline Respiratory Rate $>20$ & $26(5.4)$ \\
\hline Systolic Blood Pressure $>100$ & $452(94.6)$ \\
\hline Systolic Blood Pressure $<100$ & $26(5.4)$ \\
\hline Oxygen Saturation <92\% & $4(0.8)$ \\
\hline Recent Visits (past 30 days) & $74(15.5)$ \\
\hline Recent Admissions (past 30 days) & $38(7.9)$ \\
\hline \multicolumn{2}{|l|}{ Disposition } \\
\hline Home** & $467(97.7)$ \\
\hline Admitted to Hospital & $11(2.3)$ \\
\hline Transferred to ICU & $1 / 11(9.1)$ \\
\hline $\begin{array}{l}\text { In-Hospital Mortality (Admitted } \\
\text { patients) }\end{array}$ & 4/11 (36.4) \\
\hline In-Hospital Mortality (All patients) & $4 / 478(0.8)$ \\
\hline ED Revisit (within 30 days) & 81 (16.9) \\
\hline \multicolumn{2}{|c|}{$\begin{array}{l}{ }^{*} n(\%) \text { or mean, } S D \text { as specified } \\
\text { **Disposition home includes nursing home/institution from which patient arrived } \text { CTAS: Canadian Triage and Acuity Scale } \\
\text { ED: emergency department }\end{array}$} \\
\hline
\end{tabular}

independent variables, arrival by ambulance, had a statistically significant association with the outcome of interest (OR $=0.25$ [95\% CI: 0.06-0.99]). Of the 81 patients who returned to the ED within 30 days of their index visit, 45 (55.6\%) were admitted to hospital with a variety of diagnoses. None of the patients who returned
Table 2. Most common diagnoses.

\begin{tabular}{lc} 
Diagnosis & $\begin{array}{c}\text { Frequency } \\
(\mathrm{n}, \%)\end{array}$ \\
\hline Urinary Tract Infection (UTI) & $54(11.3)$ \\
Transient Ischemic Attack (TIA) & $48(10.0)$ \\
Dehydration & $27(5.6)$ \\
Fall & $20(4.1)$ \\
Abdominal Pain Not Yet Diagnosed & $19(4.0)$ \\
Stroke & $19(4.0)$ \\
Social Issue & $13(2.7)$ \\
Vertigo & $11(2.3)$ \\
Constipation & $10(2.1)$ \\
Chest Pain Not Yet Diagnosed & $9(1.9)$ \\
Pneumonia & $9(1.9)$ \\
Syncope & $8(1.7)$ \\
Anemia & $7(1.5)$ \\
Other $n=224$ (46.9\%) (Examples: hypotension, & $<1.5$ \\
$\quad$ drug side-effects, hypoglycemia, COPD, cancer, & \\
electrolyte disturbance) &
\end{tabular}

to the ED and were admitted died in hospital and only two of the $81(2.5 \%)$ had no subsequent hospital contact.

\section{LIMITATIONS}

A limitation of our study is that data collection was dependent on the triage CEDIS complaint. The Canadian Emergency Department Information System (CEDIS) Presenting Complaint List (version 1.1) lists 165 complaints and corresponding ICD-10 codes divided into 17 major categories. ${ }^{14}$ Although the adoption of CEDIS in EDs across Canada underscores its utility and acceptance, its validity and reliability have not been measured. The selected CEDIS complaint for each patient may have been different from the patient's presenting complaint recorded in the triage notes. In cases where the free text described a specific complaint, we selected that as the presenting complaint over the CEDIS NSC. This resulted in exclusion of patients who were categorized as having CEDIS complaint of "general weakness," "fatigue," or "feeling unwell," but who had more specific chief complaints, such as left arm weakness. An additional limitation is that the triage nurse in each case might have selected a specific CEDIS presenting complaint when the free text suggested an NSC. Whether the CEDIS complaint should have been selected in these cases cannot be determined in a retrospective study of this nature. Hence, the potential 


\begin{tabular}{llcccc|}
\hline Table 3. CTAS score and adverse events. & $\begin{array}{c}\text { Number of Patients } \\
(\mathrm{n}, \%)\end{array}$ & $\begin{array}{c}\text { Admission to Hospital } \\
(\mathrm{n}, \%)\end{array}$ & $\begin{array}{c}\text { Admission to ICU } \\
(\mathrm{n}, \%)\end{array}$ & $\begin{array}{c}\text { In-Hospital Death } \\
(\mathrm{n}, \%)\end{array}$ & $\begin{array}{c}\text { ED Revisit in } 30 \text { Days } \\
(\mathrm{n}, \%)\end{array}$ \\
$\begin{array}{l}\text { CTAS Score } \\
(\mathrm{I}-\mathrm{V})\end{array}$ & $7(1.46)$ & $2(28.57 \%)$ & 0 & $2(28.57 \%)$ & $1(14.28 \%)$ \\
I: Resuscitation & $58(12.1)$ & $2(3.45 \%)$ & $1(1.72 \%)$ & $1(1.72 \%)$ & $10(17.24 \%)$ \\
II: Emergent & $362(75.7)$ & $3(0.83 \%)$ & 0 & $1(0.27 \%)$ & $63(17.40 \%)$ \\
III: Urgent & $49(10.2)$ & $3(6.12 \%)$ & 0 & $1(2.04 \%)$ & $7(14.28 \%)$ \\
IV: Less Urgent & $1(0.21)$ & $1(100 \%)$ & 0 & 0 & 0 \\
V: Non-Urgent & & & &
\end{tabular}

Table 4. Results of logistic regression analysis for predictors of admission to hospital.

\begin{tabular}{lc|}
\hline Independent Variable & Odds Ratio $(95 \% \mathrm{Cl})$ \\
\hline Abnormal Vital Signs & $1.23(0.32-4.76)$ \\
Age & $0.98(0.88-1.09)$ \\
Male & $0.90(0.27-3.08)$ \\
Recent ED Visit or Admission & $0.70(0.14-3.39)$ \\
CTAS 1 or 2 & $0.61(0.08-4.95)$ \\
Arrival by Ambulance & $0.25(0.06-0.99)$
\end{tabular}

discord between CEDIS complaint and presenting complaint may have led to exclusion of eligible subjects.

Initially, we did include "dizziness" as a non-specific CEDIS complaint, but upon further review of medical charts, we found that presenting complaints were specific for vertigo, and thus all dizziness cases were excluded. This may have potentially missed some patients who presented with dizziness secondary to central neurological issues, although our results suggest that TIAs are still a common diagnosis for NSCs regardless of whether the CEDIS complaint of dizziness was included.

Another limitation of our study is that we looked at ED discharge diagnosis, but did not look further for additional diagnoses in hospital, or upon outpatient follow-up visits, unless the patient returned to the $\mathrm{ED}$ within 30 days of the index visit. Often, ED discharge diagnosis was "weakness NYD (not yet diagnosed)," which refers to a diagnosis of weakness for which no specific etiology has yet been found. Had longer follow-up been possible, it seems likely that some of these cases may have progressed to a more serious diagnosis or outcome.

There were only 11 outcomes of interest in the regression analysis, whereas ideally at least 60 outcomes would have been observed for an adequate model that avoided overfitting. ${ }^{15}$ This was the cause of the wide confidence intervals in the independent variables analyzed. In this context, the significant independent variable, arrival by ambulance, has become difficult to interpret. This finding may be because ambulance use may be due to factors that do not necessarily cause admission, such as long-term care residency, mobility, and social issues. ${ }^{16}$

Finally, we did not follow up on all patients after ED discharge, and so cannot comment on their actual risk. To do so would require a prospective study and adjudication on whether any adverse event was actually related to the index ED visit, as the elderly are known to have higher rates of adverse events regardless of presenting complaint.

\section{DISCUSSION}

The majority of patients with NSCs in our study presented with generalized weakness and, although the most common diagnoses were UTI, TIA, and dehydration, the frequencies of these diagnoses were not high enough to comment on disease patterns, as there were no clearly predominant diagnoses. In contrast to other studies, our results suggest that elderly patients who present to the ED with NSCs do not share a predominant diagnosis and are not necessarily at a high risk of adverse outcomes.

This discrepancy between our findings and those of other studies, most of which were conducted in Europe, may be due to the definition and application of the NSC label. In one of the most prominent studies, the Basal Non-Specific Complaints (BANC) study, NSC was defined as "all complaints that are not part of a set of specific complaints, or signs, or where an initial working diagnosis cannot be definitively established," and applied following physician assessment and validated by an expert panel. ${ }^{17}$

The higher adverse outcome rate reported in the BANC study may also be explained by their inclusion of only high-acuity patients, as determined by an Emergency Severity Index (ESI) score of 1 or 2. 
The ESI is a five-level triage score (level 1, requiring immediate life-saving intervention, and level 5, not requiring any ED resources). While the ESI differs from CTAS in that it is a resource-based triage algorithm, we have found and reported previously that the two scores mirror each other. ${ }^{18,19}$ Hence, had we only included CTAS level 1 and 2 elderly NSC patients, we would likely have observed a higher risk of adverse outcomes, as indicated by our results, which showed that $28.6 \%$ of patients with a CTAS level 1 were admitted to hospital, or had an in-hospital death. As our results show, most patients in our study were categorized as CTAS 3 (urgent). This group of patients was most likely to return to the ED within 30 days of hospital discharge.

Several predictive models have been studied in elderly patients presenting to the ED to determine hospital admission and outcome. The Identification of Seniors at Risk (ISAR) screening tool is a six-item questionnaire designed to assess for functional decline and has been found to accurately identify patients most likely to return to the ED within 30 days of index visit. ${ }^{5}$ It has also been found to predict admission to hospital, mortality, and decreased functional status after followup at four months and six months. ${ }^{7}$ The Triage Risk Screening Tool (TRST) is a prospectively derived and validated five-item screening tool $^{20}$; however, a prospective study at our study sites found that the TRST has insufficient diagnostic accuracy to predict whether Canadian ED elders will have an ED revisit, hospital admission, or long-term care placement at 30 or 120 days. $^{21}$ We were unable to identify any reliable predictors of outcome from our chosen independent variables, but this was almost certainly because of our low outcome event rate, and thus a much larger sample would be required for future studies addressing this question.

Finally, our study patients' relatively high ED revisit rate of $16.9 \%$ is consistent with the $19.3 \%$ rate of all elderly patients visiting the ED regardless of presenting complaint, further supporting the notion that elderly patients presenting with NSCs are at no greater risk of ED return visit. It is difficult to interpret the high admission rate of $55.5 \%$ following return visit. Although it was tempting to conclude that the patients were more unwell at this point, this may not be the case. In some cases, these patients may have been admitted for further workup of a non-resolving issue. In fact, the 45 patients admitted after return to ED may not have been as sick than other patients since none of them died in hospital, compared to four of 11 patients who were admitted directed from the ED and subsequently died.

The diagnosis and disposition of elderly patients with NSCs remains a challenge for emergency physicians due to the complexity of both social and medical issues prevalent in this group. However, there appears to be no reason to believe that elderly patients presenting with NSCs are at any higher risk of an adverse outcome than those presenting with a specific complaint and, in some cases, they may even be less so.

\section{CONCLUSION}

Our results suggest that elderly patients presenting to the ED with non-specific complaints are not at high risk for life-threatening illnesses. The most common diagnoses are UTI, TIA, and dehydration. Most patients can be discharged safely, although a relatively high proportion revisit the ED within 30 days.

Acknowledgments: This article was originally presented at the CAEP 2013 Annual Conference in Vancouver, British Columbia.

Competing Interests: None to declare.

\section{REFERENCES}

1. Strange GR, Chen EH, Sanders AB. Use of emergency departments by elderly patients: projections from a multicenter data base. Ann Emerg Med 1992;21(7):819-24.

2. Aminzadeh F, Dalziel WB. Older adults in the emergency department: a systematic review of patterns of use, adverse outcomes, and effectiveness of interventions. Ann Emerg Med 2002;39(3):238-47.

3. LaMantia MA, Platts-Mills TF, Biese K, et al. Predicting hospital admission and returns to the emergency department for elderly patients. Acad Emerg Med 2010;17(3):252-9.

4. McCusker J, Bellavance F, Cardin S, et al. Prediction of hospital utilization among elderly patients during the 6 months after an emergency department visit. Ann Emerg Med 2000;36(5):438-45.

5. McCusker J, Cardin S, Bellavance F, et al. Return to the emergency department among elders: patterns and predictors. Acad Emerg Med 2000;7(3):249-59.

6. Nemec M, Koller MT, Nickel CH, et al. Patients presenting to the emergency department with non-specific complaints: The Basel Non-specific Complaints (BANC) study. Acad Emerg Med 2010;17(3):284-92.

7. Samaras N, Chevalley T, Samaras D, et al. Older patients in the emergency department: a review. Ann Emerg Med 2010;56(3):261-9. 
8. Vanpee D, Swine C, Vandenbossche P, et al. Epidemiological profile of geriatric patients admitted to the emergency department of a university hospital localized in a rural area. Eur 7 Emerg Med 2001;8(4):301-4.

9. Rutschmann OT, Chevalley T, Zumwald C, et al. Pitfalls in the emergency department triage of frail elderly patients without specific complaints. Swiss Med Wkly 2005;135(9-10):145-50.

10. Safwenberg U, Terént A, Lind L. The Emergency Department presenting complaint as predictor of in-hospital fatality. Eur 7 Emerg Med 2007;14(6):324-31.

11. Nickel C H, Ruedinger JM, Messmer AS, et al. Drug-related emergency department visits by elderly patients presenting with non-specific complaints. Scand 7 Trauma Resusc Emerg Med 2013;21:15.

12. Worster A, Bledsoe RD, Cleve P, et al. Reassessing the methods of medical record review studies in emergency medicine research. Ann Emerg Med 2005;45(4):448-51.

13. Worster A, Haines T. Advanced statistics: understanding medical record review (MRR) studies. Acad Emerg Med 2004;11(2):187-92.

14. Grafstein E, Bullard M, Unger B, et al. Revision of the Canadian Emergency Department Information System (CEDIS) Presenting Complaint List version 1.1. CFEM 2008;10(2):151-61.
15. Stoltzfus JC. Logistic regression: a brief primer. Acad Emerg Med 2011;18(10):1099-104.

16. Shah MN, Glushak C, Karrison TG, et al. Predictors of emergency medical services utilization by elders. Acad Emerg Med 2003;10(1):52-8.

17. van Bokhoven MA, Koch H, van der Weijden T, et al. Special methodological challenges when studying the diagnosis of unexplained complaints in primary care. 7 Clin Epidemiol 2008;61(4):318-22.

18. Worster A, Fernandes CM, Eva K, et al. Predictive validity comparison of two five-level triage acuity scales. Eur 7 Emerg Med 2007;14(4):188-92.

19. Worster A, Gilboy N, Fernandes CM, et al. Assessment of inter-observer reliability of two five-level triage and acuity scales: a randomized controlled trial. CFEM 2004;6(4):240-5.

20. Meldon SW, Mion LC, Palmer RM, et al. A brief risk-stratification tool to predict repeat emergency department visits and hospitalizations in older patients discharged from the emergency department. Acad Emerg Med 2003; 10(3):224-32.

21. Fan J, Worster A, Fernandes CMB. Predictive validity of the Triage Risk Screening Tool for elderly patients in a Canadian emergency department. Am 7 Emerg Med 2006; 24(5):540-4. 